\title{
Design Methodology of Novel PID for Efficient Integration of PV Power to Electrical Distributed Network
}

\author{
D. Gueye*, A. Ndiaye*๋, M. Abdou Tankari**, M. Faye*, A. Thiam*, L. Thiaw***, G. Lefebvre** \\ *Rearch team energetic system and efficiency, Alioune Diop University of Bambey, BP 30, Senegal \\ **CERTES Laboratory, University of Paris Est Creteil, 61, Avenue Général de Gaulle, 94010, Creteil cedex, France \\ *** Laboratoire d'Energies Renouvelables, Ecole Supérieure, Université Cheikh Anta diop BP 5085 Dakar Fann, Senegal
}

(daouda.gueye2@uadb.edu.sn, alphousseyni.ndiaye@uadb.edu.sn, mahamadou.abdou-tankari@u-pec.fr)

$¥$ Corresponding Author; Daouda Gueye Thies 21000, Tel: +221 7781323 61, Second Author; Alphousseyni Ndiaye Parcelles Assainies unité 10 numéro 200-Dakar, Tel: +221 772262315.

Received: 20.03.2018 Accepted28.03.2018

\begin{abstract}
This work is devoted to the study of a photovoltaic system connected to the distribution grid. The objective is to propose a new corrector for the control of a three-phase inverter connected to the distribution grid in order to obtain an optimal injection of photovoltaic energy. The system consists of a photovoltaic generator, a DC/DC boost converter and a three-phase inverter connected to the grid via a transformer. In first, a system modeling has established the mathematical models of the different components of the conversion chain. A local method of research maximum power point of the incremental conductance type $(\mathrm{InC})$ is then developed. Furthermore, a control in the synchronous reference frame d-q by a modified PID controller is offered to regulate the currents injected by the three-phase inverter compared to conventional PI and PID controllers. Simulation results from the system under the Matlab/Simulink environment prove the efficiency of the MPPT control and show that the currents injected with the modified PID controller have a the best sinusoidal form with a harmonic distortion rate (TDH) of $2.39 \%$.
\end{abstract}

Keywords- Photovoltaic systems, Three-phase inverter, Modified PID, Classic PID, PI.

Table 1. Nomenclature

\begin{tabular}{|c|c|c|c|c|c|}
\hline Symbols & Meanings & Symbols & Meanings & Symbols & Meanings \\
\hline $\mathrm{V}_{\mathrm{pv}}$ & PV voltage & $\mathrm{R}$ & Inverter filter resistance & $\mathrm{K}_{\mathrm{p}}$ & Proportional gain \\
\hline $\mathrm{I}_{\mathrm{pv}}$ & PV current & $\mathrm{L}$ & Inverter filter inductance & $\mathrm{K}_{\mathrm{i}}$ & Integral grain \\
\hline $\mathrm{C}_{1}$ & Output filter PV capacity & $\mathrm{I}_{\mathrm{d}, \mathrm{q}}$ & Active and reactive current & $\mathrm{K}_{\mathrm{d}}$ & Derivative gain \\
\hline $\mathrm{C}_{2}\left(\mathrm{C}_{\mathrm{dc}}\right)$ & DC link capacity & $\mathrm{V}_{\mathrm{d}, \mathrm{q}}$ & Active and reactive voltage & $\tau$ & Constant time \\
\hline $\mathrm{L}_{\mathrm{h}}$ & Boost inductance & $\mathrm{V}_{\mathrm{dc}}$ & DC link voltage & $\mathrm{T}_{\mathrm{i}}$ & Constant of integration \\
\hline $\mathrm{I}_{\mathrm{L}}$ & Boost inductance current & $\mathrm{I}_{\mathrm{a}}, \mathrm{I}_{\mathrm{b}}, \mathrm{I}_{\mathrm{c}}$ & Output inverter current & $\mathrm{T}_{\mathrm{d}}$ & Constant of derivation \\
\hline $\mathrm{V}_{\mathrm{a}}, \mathrm{V}_{\mathrm{b}}, \mathrm{V}_{\mathrm{c}}$ & Inverter simple voltage & $\mathrm{Idc}_{\mathrm{f}}\left(\mathrm{I}_{\mathrm{C} 2}\right)$ & DC link current & $\mathrm{K}_{\mathrm{cr}}$ & Critical gain \\
\hline $\mathrm{E}_{\mathrm{a}}, \mathrm{E}_{\mathrm{b}}, \mathrm{E}_{\mathrm{c}}$ & Grid voltage & $\omega$ & Pulsation & $\mathrm{T}_{\mathrm{cr}}$ & Critical period \\
\hline$\omega_{0}$ & Own pulsation & $\xi$ & Damping coefficient & $\alpha$ & Duty cycle \\
\hline
\end{tabular}




\section{Introduction}

Today global energy demand continues to increase because of the economic development of the country but also to population growth. This request was provided in full by non-renewable energy: fossil fuels [1]. The latter, becoming increasingly rare, are causing global warming by the emission of greenhouse gases (GHGs). Following this realization, research work is oriented to other technical or production methods to protect the environment and sufficient energy supply. Renewable energies (solar, wind etc ...) represent an undeniable solution to answer the world's energy requirements [2]. Among them, solar photovoltaic, a renewable energy source able to answer some of the current energy needs [3]. It is the direct transformation of part of solar radiations into electricity [1].

However, the photovoltaic (PV) energy injection to the power line is a very complex phenomenon and is possible only by means of static electronic power converters (DC / $\mathrm{DC}$ and $\mathrm{DC} / \mathrm{AC}$ ). The fluctuating nature of the PV source and the nonlinearity of the electrical characteristic is a headache. This nonlinearity generates maximum instantaneous power towards changes in weather conditions. Hence, it's necessary to know how to approach such a system to optimize power delivery. On the other hand, the three-phase inverter provides power conversion to $\mathrm{AC}$ power. It participates in the influence of the energy quality injected by a significant harmonic distortion in the current and the overall performance of the system. Thus improving their performance will always remain an objective. This scenario leads to the goal where the work is performed registered in this article, which is the design and synthesis of operating a three-phase inverter in order to obtain a flexible injection of maximum power extracted with operation at unity power factor.

In this perspective, different control techniques dedicated to the three-phase inverters have been proposed. The control by hysteresis, due to its robustness and simple implementation, is used as a direct control current (DCC) [4, 5]. Simulation results give a harmonic distortion (THD) current of $2.61 \%$ [5]. Unlike in [3] where it is used as a direct power control. It is to control the active and reactive power. Despite its performances, variable switching frequency remains the main problem.

N. Hamrouni [6] has an inner loop current to control the output currents of a three-phase inverter via a PI controller in the base Park. Simulation results show a THD below international standards (THD $<5 \%$ ) and the presence of harmonics at high frequencies on the current injected to the network.

The quality of the energy injected to the grid is improved by the intervention of smart technologies that play a very important role there. The modulated hysteresis control [7] and hybrid controls [8, 9, 10] have been developed to overcome the limits of conventional controls. They have better performance than conventional. For example neural PI control (PI with APDLINE (Adaptive, LINear Element)) and the hysteresis control respectively provide current THD of $1.4 \%$ and $3.38 \%$ [9].

In order to improve the quality of the energy fed to the grid, other techniques have been developed. Among them, predictive direct flux control (PDFC) [11] study the behaviour of the flow that is the position and amplitude of the inverter flux in order to minimize the flux of the undulation and to improve their performance. Simulation results show the effectiveness of PDFC with a current THD of $4.09 \%$ compared to $12.15 \%$ of the conventional technique SDFC method.

Furthermore, it should be noted that the conversion chain of a PV system is the same, single control techniques are enhanced [3]. In this study, the control in the d-q synchronous reference frame (basic Park) with a modified PID controller is proposed. Similarly, to extract the maximum power of GPV, a control algorithm InC kind local MPPT is used.

So for a detailed development, section 1 presents the modeling and design of the system. Section 2 presents the system control strategy. The simulation results obtained under the Matlab/Simulink are presented and discussed in Section 3. Finally, Section 4 is based on a comparative study of the performance and robustness of the modified PID controller with PI and conventional PID.

\section{Modeling and control of the boost converter}

\subsection{Modeling of the boost converter}

This is a DC / DC converter which convert between a current DC source and a DC voltage source [12]. The use of the boost converter is explained by the fact that the voltage delivered by the GPV is below the desired voltage DC link.

Knowledge of mathematical models is still important to study the behaviour of such a converter. These models will be detailed by conduction sequence.

\section{$1^{\text {st }}$ conduction sequence}

This sequence corresponds to the $\mathrm{K}$ switch conduction phase that is the energy storage phase in magnetic form.

Kirchhoff's laws have established the equations (1): 


$$
\begin{aligned}
& \left\{\begin{array}{l}
C_{1} \frac{d V_{p v}}{d t}=I_{p v}-I_{L} \\
\frac{d I_{L}}{d t}=\frac{V_{p v}}{L_{h}}
\end{array}\right. \\
& >2^{\text {nd }} \text { conduction sequence }
\end{aligned}
$$

This part corresponds to the opening of the switch $\mathrm{K}$, the diode conducts. Applying the laws of Kirchhoff includes the relationships of equations (2):

$$
\left\{\begin{array}{l}
C_{1} \frac{d V_{p v}}{d t}=I_{p v}-I_{L} \\
L_{h} \frac{d I_{L}}{d t}=V_{p v}-V_{d c}
\end{array}\right.
$$

\subsection{Control boost converter}

To improve the performance of PV systems, operating at maximum power point is necessary. Therefore, MPPT control algorithm type incremental conductance ( $\mathrm{InC}$ ) thanks to its good performance [13] is associated with the boost converter in order to extract the maximum instantaneous power some is the variation. The principle of the control diagram is shown in Fig. 1.

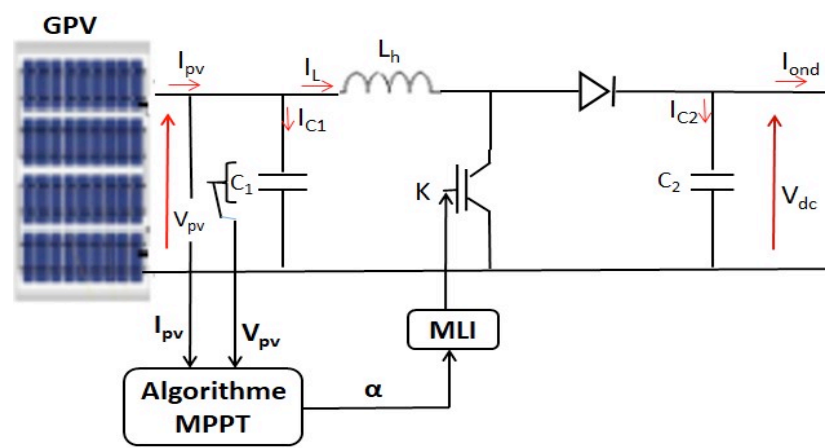

Fig. 1. The control loop of the stage DC / DC

\subsubsection{Algorithm of MPPT control based on $\operatorname{InC}$}

The InC method is a method based on the variation of the power with respect to voltage. This variation can locate the operating point relative to the MPP. It is expressed in terms of voltage and current as follows:

$$
P_{p v}=V_{p v} I_{p v}
$$

$$
\frac{\Delta P_{p v}}{\Delta V_{p v}}=\frac{\Delta\left(V_{p v} I_{p v}\right)}{\Delta V_{p v}}=I_{p v} \frac{\Delta V_{p v}}{\Delta V_{p v}}+V_{p v} \frac{\Delta I_{p v}}{\Delta V_{p v}}
$$

$$
\frac{\Delta P_{p v}}{\Delta V_{p v}}=I_{p v}+V_{p v} \frac{\Delta I_{p v}}{\Delta V_{p v}}
$$

The MPP can be followed by comparing the measured values at iteration $\mathrm{k}$ values of the $\mathrm{k}-1$ and these quantities are defined by the following equations (6) and (7) [14]:

$$
\begin{aligned}
& \Delta V_{p v}(k) \approx V_{p v}(k)-V_{p v}(k-1) \\
& \Delta I_{p v}(k) \approx I_{p v}(k)-I_{p v}(k-1)
\end{aligned}
$$

Thus, to determine the MPP, the algorithm is based on the conditions of the equation (8) if $\Delta V_{p v}(k) \neq 0$ and the conditions of equations (9) if $\Delta V_{p v}(k)=0$.

$$
\begin{aligned}
& \frac{\Delta I_{p v}}{\Delta V_{p v}}=-\frac{I_{p v}}{V_{p v}} \quad \text { and } \frac{\Delta I_{p v}}{\Delta V_{p v}} \neq-\frac{I_{p v}}{V_{p v}} \\
& \Delta I_{p v}=0 \quad \text { and } \quad \Delta I_{p v} \neq 0
\end{aligned}
$$

If the first relationship of equations (8) and (9) are checked, the point is reached otherwise $\mathrm{V}_{\mathrm{pv}}(\mathrm{k})$ is either higher or lower than the optimum voltage $\mathrm{Vm}$, hence the need to increase or decrease the duty cycle. The schematic diagram, that is, the flowchart of command detailing the various options is given in Fig. 2.

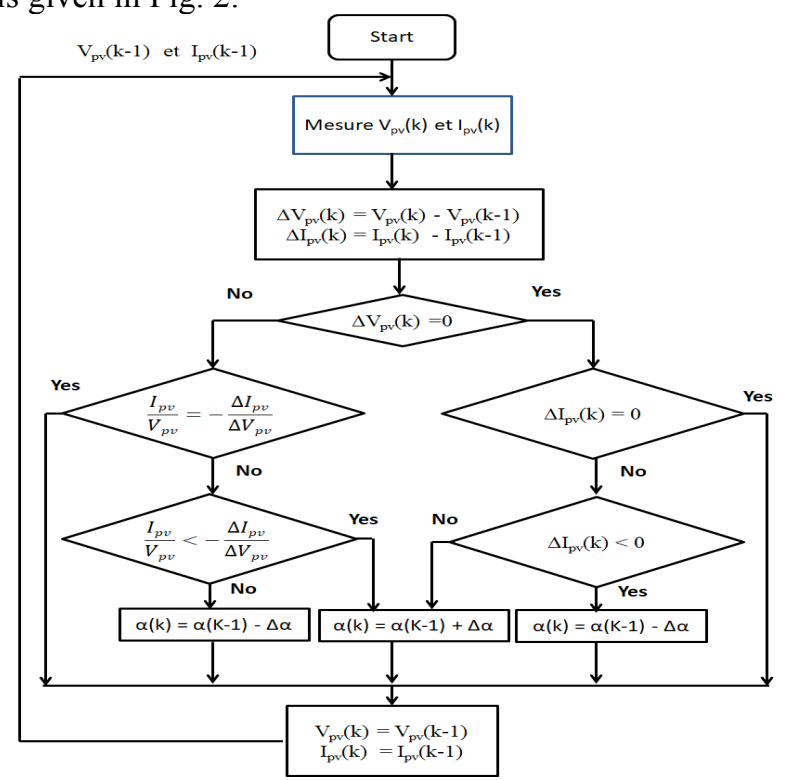

Fig. 2. Organization of the method INC [15]

\section{Modeling and three-phase inverter control}

\subsection{Modeling the three-phase inverter}

The inverter is an important part (or even essential) in the conversion chain of PV systems connected to the grid. It is a power electronics device that allows processing of continuous electrical energy (DC) from the GPV to electric power type AC. It cites the single phase inverters, designed 


\section{Gueye et al., Vol.2, No.1, March, 2018}

for single-phase loads and three-phase inverters which are the subject of our study.

The modeling of the three-phase inverter is obtained by the phase voltages provided by the differential equations:

$$
\left\{\begin{array}{l}
V_{a}=L \frac{d I_{a}}{d t}+R I_{a}+E_{a} \\
V_{b}=L \frac{d I_{b}}{d t}+R I_{b}+E_{b} \\
V_{c}=L \frac{d I_{c}}{d t}+R I_{c}+E_{c}
\end{array}\right.
$$

However to control the output of the three-phase inverter via conventional regulators such as P, PI or PID, transform Park remains necessary because they are not suitable for applications controls AC signals. This transformation simplifies the model that is; replace the variables by threephase two-phase variables that will be seen as continuous variables in the d-q coordinate system [16]. The application of the Park transform the three-phase system gives the following relationships:

$$
\left\{\begin{array}{l}
T_{P} X_{a b c}=X_{d q} \\
T_{P} \frac{d X_{a b c}}{d t}=T_{P} \frac{d T_{P}^{-1}}{d t} X_{d q}-\frac{d X_{d q}}{d t}
\end{array}\right.
$$

With $X_{d q}=\left[X_{d} X_{q}\right]^{T}$ et $X_{a b c}=\left[X_{a} X_{b} X_{c}\right]^{T}$ or X is a voltage or a current.

$$
T_{P}=\frac{2}{3}\left[\begin{array}{l}
\cos \theta \cos \left(\theta-\frac{2 \pi}{3}\right) \cos \left(\theta-\frac{4 \pi}{3}\right) \\
-\sin \theta-\sin \left(\theta-\frac{2 \pi}{3}\right)-\sin \left(\theta-\frac{4 \pi}{3}\right)
\end{array}\right]
$$

is the Park's matrix.

Thus, through this transformation, the study of the threephase variables is summarized in the following two-phase in the $d-q$ reference:

$$
\left\{\begin{array}{l}
V_{d}=L \frac{d I_{d}}{d t}+R I_{d}+E_{d}-L \omega I_{q} \\
V_{q}=L \frac{d I_{q}}{d t}+R I_{q}+E_{q}-L \omega I_{d}
\end{array}\right.
$$

\section{2. $\quad$ Three phase inverter control}

In order to achieve a flexible and reliable injection of the maximum power extracted to the grid with a unity power factor, regulating the DC bus voltage and the inverter output currents is required. Thus, control of the DC link voltage and output the three-phase inverter currents is done by conventional PI, PID controllers and the modified PID controller. The overall structure of the inverter control is given in Fig. 3.

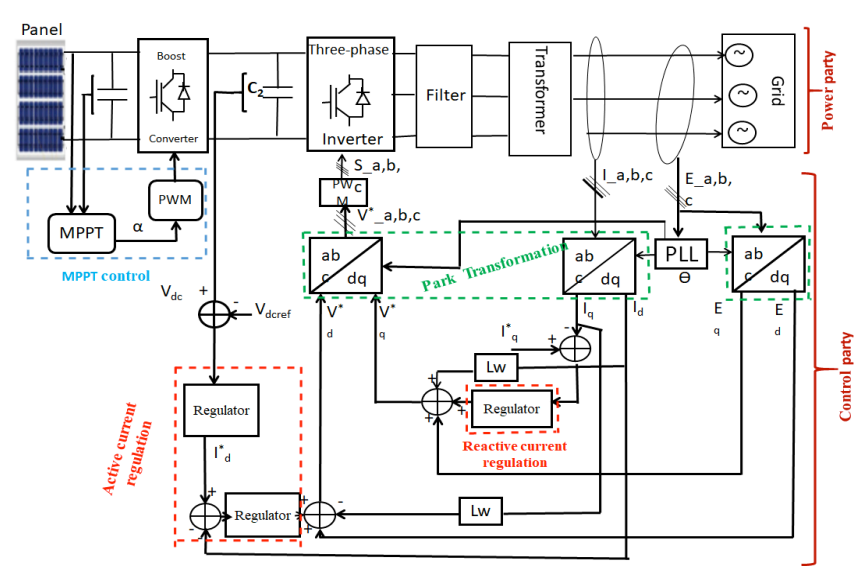

Fig. 3. Diagram of the three-phase inverter control

\subsubsection{Regulating synthesis of DC link voltage}

The voltage $\mathrm{V}_{\mathrm{dc}}$ is a very important element for the inverter as its constancy helps improve their performance. Thus the fluctuations of it should be low, hence the need to use a controller. This regulation will minimize influences due to climatic variations on the DC bus voltage.

The equation of the DC current flowing on the link and the Laplace transform are given by the following relationship:

$$
\left\{\begin{array}{l}
I_{d c}=C_{d c} \frac{d V_{d c}}{d t} \\
V_{d c}(p)=\frac{1}{p C_{d c}} I_{d c}(p)
\end{array}\right.
$$

\subsubsection{The PI controller}

With its simplicity and the possibility to cancel the static error, the classic proportional integral corrector (PI) is widely used in continuous systems. It is a combination of proportional and integral corrector PI. The transfer function of such a controller is described by equation (14): 


$$
G(p)=K_{p}+\frac{K_{i}}{p}
$$

For a good correction of the system, sizing parameters $\mathrm{Kp}$ and $\mathrm{Ki}$ becomes necessary. They can be obtained through the control loop shown in Fig. 4.

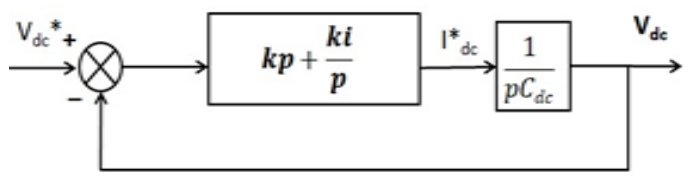

Fig. 4. The voltage control loop $\mathrm{V}_{\mathrm{dc}}$

The transfer function of the open loop control loop is given by equation (15).

$$
H_{v B O}(p)=\frac{p K_{p}+K_{i}}{p} \frac{1}{p C_{d c}}
$$

And performing a closed loop, the equation (16) is obtained:

$$
H_{v B F}(p)=\frac{p K_{p}+K_{i}}{p^{2} C_{d c}+p K_{p}+K_{i}}
$$

Equation (16) has only one zero and two poles. Fixing the poles allows to determine the parameters of the PI controller. An analogy is made with the denominator of the transfer function of a second order system given by equation (17).

$$
D(p)=p^{2}+2 \xi \omega_{0} p+\omega_{0}^{2}
$$

The adjustment parameters thus obtained are given by the equations (18).

$$
\left\{\begin{array}{l}
K_{p}=2 \xi \omega_{0} C_{d c} \\
K_{i}=\omega_{0}^{2} C_{d c}
\end{array}\right.
$$

With $\omega_{0}$ and $\xi$, the natural frequency and damping coefficient which respectively allow the setting of the response time and overshoot.

\subsubsection{The PID controller}

The PID controller, gathering the $\mathrm{P}$, I and D, is a widely used in the industry correction. The latter, with its derivative term can overcome the limitations of the PI controller to improve system stability. The transfer function of this corrector is described by the equation (19) with $\tau$ equal to the derivative constant.

$$
H(p)=K_{p}+\frac{K_{i}}{p}+\frac{K_{d} p}{1+\tau p}
$$

The control loop shown in Figure 5 enables the dimensioning of the controller parameters for a good correction voltage $\mathrm{V}_{\mathrm{dc}}$.

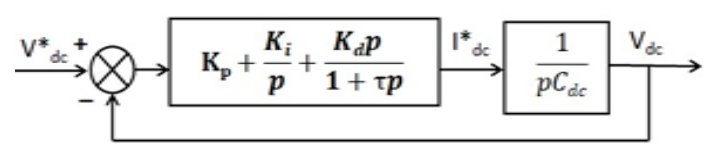

Fig. 5. The voltage control loop $\mathrm{V}_{\mathrm{dc}}$

\subsubsection{The modified PID controller}

Since the PID controller, the modified PID controller combines the P, D. Unlike the PID controller and I, it adds a high frequency low-pass filter to each term in order to make it more immune to noise. Thus the transfer function of such a correction is given by equation (20).

$$
H(p)=\frac{1}{1+\tau p}\left(K_{p}+\frac{K_{i}}{p}+K_{d} p\right)
$$

The control loop for the dimensioning of parameters is given in Figure 6.

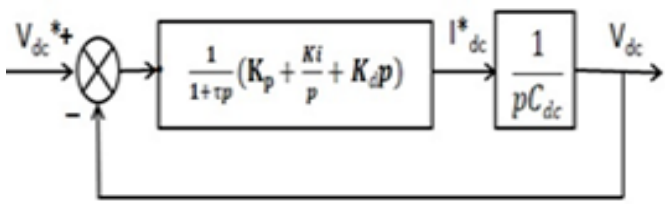

Fig. 6. The voltage control loop Vdc

\subsubsection{Index and frequency analysis of the three- phase inverter}

The time and frequency analysis are complementary methods. They allow respectively to study the behaviour of a system over time and frequency. In this work, an index analysis is done to study the temporal behaviour of the inverter. This analysis is to perform a step-type input excitation.

Thus the transfer function of the three-phase inverter for the index analysis and the frequency is achieved through the transformation of Park. After simplification, time equations (21) give the transfer function of the three-phase inverter in the base of Park. Applying the Laplace transform, the transfer function is given by equation (22). 
D. Gueye et al., Vol.2, No.1, March, 2018

$$
\begin{aligned}
& \left\{\begin{array}{l}
V^{\prime}{ }_{d}=L \frac{d I_{d}}{d t}+R I_{d} \\
V_{q}^{\prime}=L \frac{d I_{q}}{d t}+R I_{q}
\end{array}\right. \\
& F_{d, q}(p)=\frac{I_{d, q}(p)}{V_{d, q}^{\prime}(p)}=\frac{1}{R+L p}
\end{aligned}
$$

The analyzes give the Figures 7 and 8 which respectively show the frequency study with the Bode diagram in an open loop step response and the closed loop of the inverter.

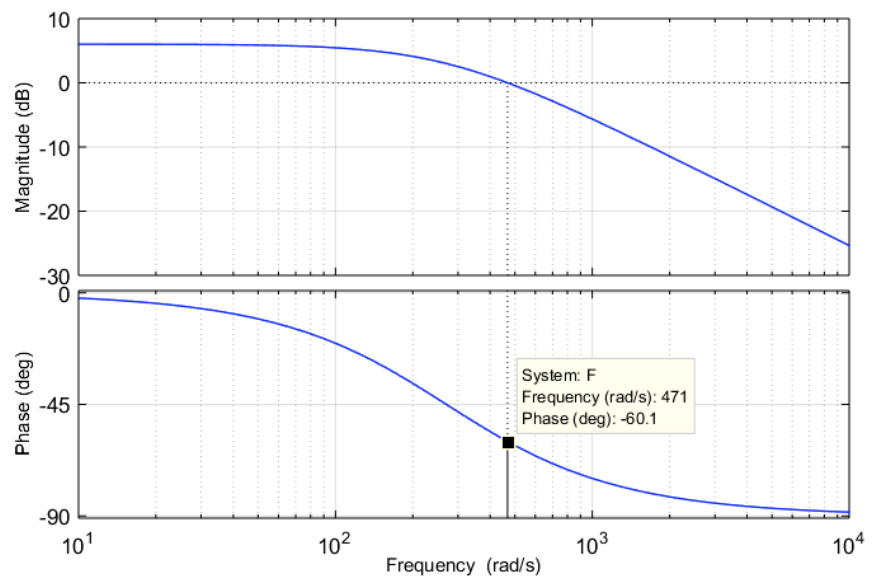

Fig. 7. Bode diagram the open loop

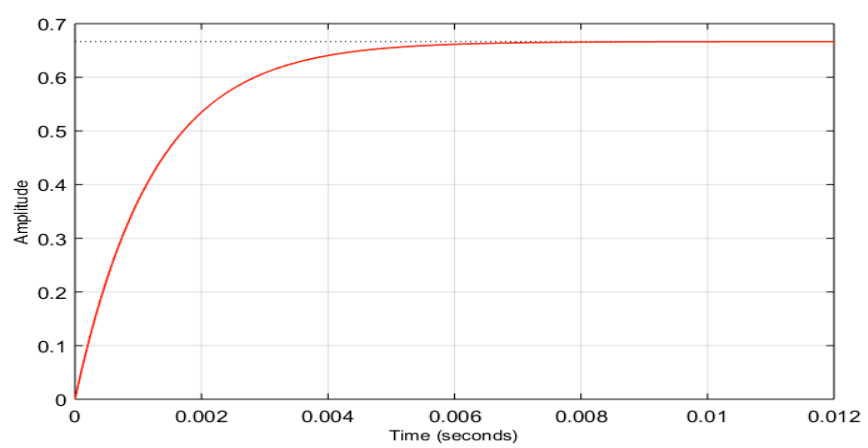

Fig. 8. Transient closed loop of the three-phase inverter

Fig. 7 shows the Bode diagram, where it changes the gain in decibels and phase depending on the pulsation. This diagram shows the stability of the closed loop system based on the criterion Revers for the place of Bode of the open loop transfer function contains a module of $0 \mathrm{~dB}$ and an argument $-60,1^{\circ} \mathrm{C}>-180^{\circ} \mathrm{C}$.

Figure 8 shows the step response of the closed loop system. This graph shows a significant static error between the set value (unit) and the response and a response time almost infinite. The correction of the step response of the inverter is represented by the curves of Figure 9.

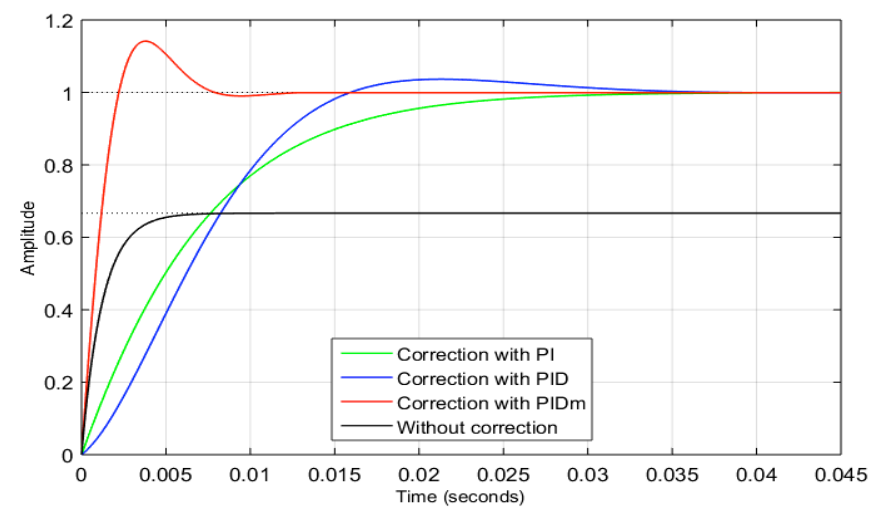

Fig. 9. Closed-loop Step Response with and without correction

Thus, these results show the need to perform a regulation of the three-phase inverter to improve performance.

\subsubsection{Synthesis regulation of current from the inverter}

In order to improve the power quality, control current of the inverter is still needed in PV systems connected to the grid. The latter allows the inverter to ensure optimal injection of the extracted power to the grid with a power factor but also with low ripple current.

The control of the output of the three-phase inverter via conventional regulators such as P, PI or PID can be changed only through the transformation of Park.

\subsubsection{The PI controller}

Always with its simplicity, the PI controller is very used in the d-q mark for control of the output currents of three-phase inverters. However, in order to simplify the current regulating loop with the PI controller is illustrated in Figure 10.

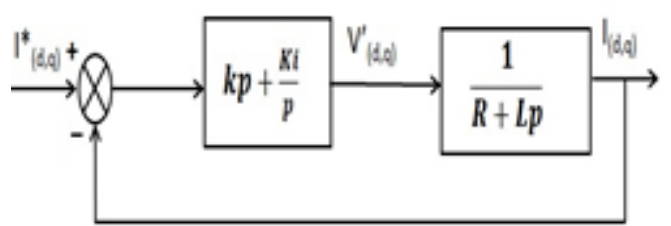

Fig. 10. Current regulating loop

The transfer function of the open loop control loop is given by equation (23).

$$
H_{i B O}(p)=\frac{p K_{p}+K_{i}}{p} \frac{1}{p L+R}
$$

And closed loop, the equation becomes:

$$
H_{i B F}(p)=\frac{p K_{p}+K_{i}}{L p^{2}+\left(R+K_{p}\right)+K_{i}}
$$




\section{Gueye et al., Vol.2, No.1, March, 2018}

As with the method of determining the voltage adjustment parameters of the DC bus, the obtained parameters are given by the equations in (25) for the regulation of currents.

$$
\left\{\begin{array}{l}
K_{p}=2 \xi \omega_{0} L-R \\
K_{i}=L \omega_{0}{ }^{2}
\end{array}\right.
$$

\subsubsection{The PID controller}

With its ability to improve both the stability and accuracy of a system, the PID controller is the most preferred despite the complication of certain industrial systems. The control loop with the PID controller is shown in Fig. 11.

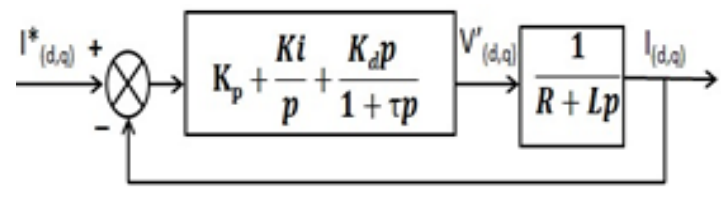

Fig. 11. Current control loop

\subsubsection{The modified PID controller}

As defined with the regulation of synthesis of the voltage $\mathrm{V}_{\mathrm{dc}}$, the modified PID controller can also be used in the base Park to ensure a regulation of the output of the three-phase inverter current. This regulation will minimize the presence of harmonic current at the output inverter. To do this the controller is used in the control loop illustrated in Fig. 12.

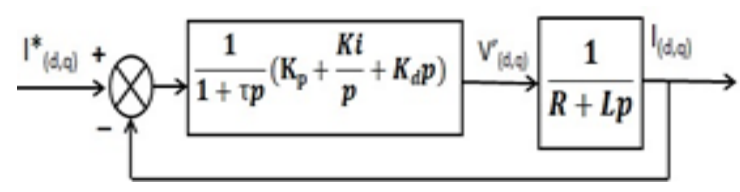

Fig. 12. Current regulating loop with the modified PID controller

\section{Determination of Parameters of PID regulator and modified PID regulator}

The corrective adjustment is paramount in order to want to meet good control of a system. For this, the method of the critical point of Ziegler-Nichols proposed for determining the parameters of conventional PID controller. The latter is to loop the system with a proportional corrector $\mathrm{P}$ wherein the gain is adjusted until a permanent oscillation. Under these conditions the system is its stability limit. The critical gain $\mathrm{K}_{\text {cr }}$ and the oscillation period $\mathrm{T}_{\text {cr }}$ are determined. Based on these variables, the parameter of the PID controller are determined as follows.

Table 2. Values of the conventional PID controller

\begin{tabular}{|l|l|}
\hline Parameters & Values \\
\hline $\mathrm{Kp}$ & $0,6 \mathrm{Kcr}$ \\
\hline $\mathrm{Ti}(\mathrm{s})$ & $0,5 \mathrm{Tcr}$ \\
\hline $\mathrm{Td}(\mathrm{s})$ & $0,125 \mathrm{Tcr}$ \\
\hline
\end{tabular}

On the other side, an experimental determination is for the modified PID controller. This method consists in varying the parameters $K_{p}$, respectively, $K_{d}$ and $K_{i}$ while moving to the right correction system. Increasing $\mathrm{K}_{\mathrm{p}}$ parameter improves the accuracy of the system, the $K_{p}$ plays a stabilizing role and $\mathrm{K}_{\mathrm{i}}$ parameter cancelling the static error. Thus, at the end of the method, the values for the proper regulation of the system are summarized in table 3 .

\section{Results and discusions}

To illustrate the behavior of the control in the synchronous reference frame by a modified PID controller, we used a PV system connected to the grid. This conversion chain is comprised of a photovoltaic field, a voltage-raising chopper controlled incremental conductance type of MPPT, a threephase inverter controlled by Pulse Width Modulation (PWM) and a three-phase transformer. A comparative study with the PI controller and PID will allow us to observe the performance of the modified PID controller. The corrective parameter ar summarized in Table 2.

Table 3. Values of the various parameters of the three correctors

\begin{tabular}{|l|c|c|c|c|c|c|}
\hline Magnitudes & \multicolumn{3}{|c|}{ Voltage Vdc } & \multicolumn{3}{c|}{ Output Current } \\
\hline Parameters & $\mathrm{Kp}$ & $\mathrm{Ki}\left(\mathrm{s}^{-1}\right)$ & $\mathrm{Kd}(\mathrm{s})$ & $\mathrm{Kp}$ & $\mathrm{Ki}\left(\mathrm{s}^{-1}\right)$ & $\mathrm{Kd}(\mathrm{s})$ \\
\hline PI & 1.8 & 13.4 & 0 & 0.24 & 74.04 & 0 \\
\hline PID & 18 & 566 & 0.15 & 0.06 & 80 & $1,12.10^{-5}$ \\
\hline PID modified & 50 & 8 & 0.5 & 0.06 & 5 & $4,12.10^{-4}$ \\
\hline
\end{tabular}


D. Gueye et al., Vol.2, No.1, March, 2018

The simulations were performed under the Matlab / Simulink environment. In order to study the performance and robustness of the correction, the system is subject to climatic variation illustrated in Fig. 13.

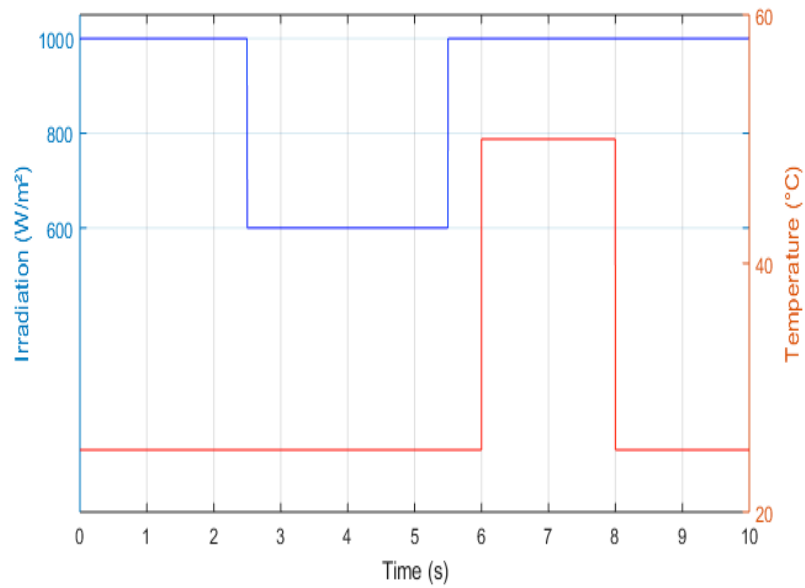

Fig. 13. Variations of irradiation and temperature

The curves in Figure 14 show that regulators prove their effectiveness by performing a net followed the DC link voltage. It goes through a transitional period lasting less than $0.9 \mathrm{~s}$ before following his reference with a maximum overshoot of $46 \%$ classic PID controller in comparison to $2.4 \%$ of modified PID controller. With the variation, the voltage makes $0.5 \mathrm{~s}$ with the PI correction before stabilizing, when the PID controllers prove their robustness against climate change.

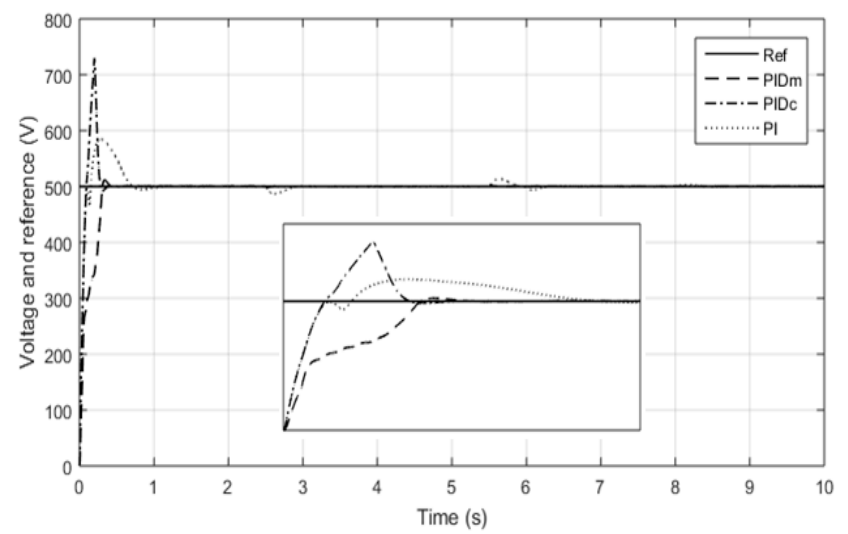

Fig. 14. Vdc voltages and reference (V)

Fig. 15 shows the effectiveness of regulators used where active currents follow their references with low overshoot and static error practically zero in steady state. The zoomed parts show that the active currents have undulations, which depend on corrector and negatively influence the quality of the injected current.

The unit power factor is justified by the curves in Fig. 16; the current and voltage are in phase despite climatic variations.
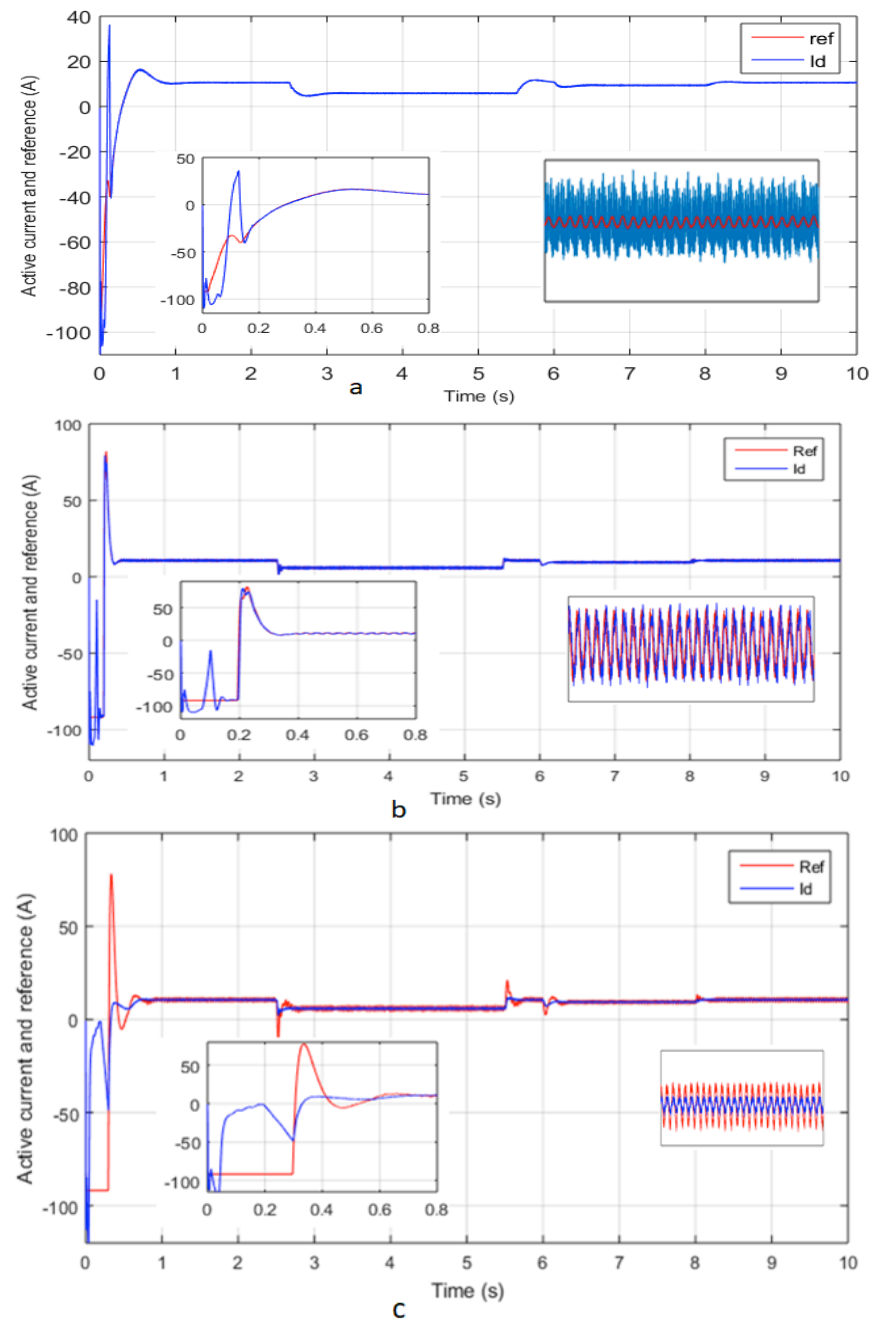

Fig. 15. Active current : a.) PI b.) PID c.) Modified PID

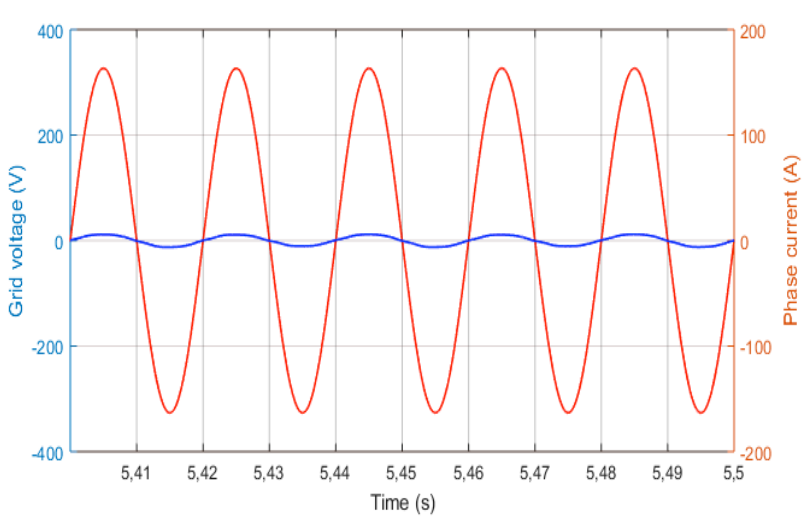

Fig. 16. Phase current and grid voltage

The curves in Fig. 17 show the total harmonic distortion (THD) of the currents injected by the three-phase inverter with the three regulators. These curves show that the threephase inverter injects a current low ripple with the modified PID controller unlike the conventional PID controller. This can be interpreted that the associated filters will make the correction insensitive to noise. 
D. Gueye et al., Vol.2, No.1, March, 2018

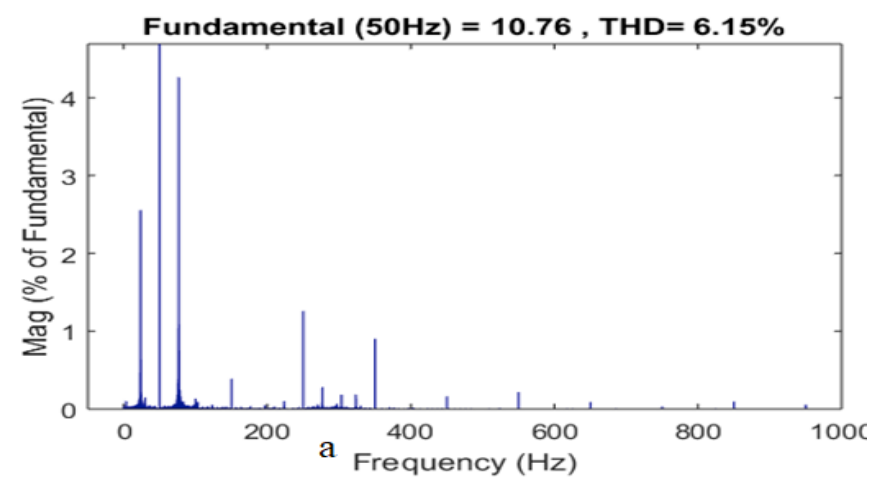

Fundamental $(50 \mathrm{~Hz})=10.73, \mathrm{THD}=3.01 \%$
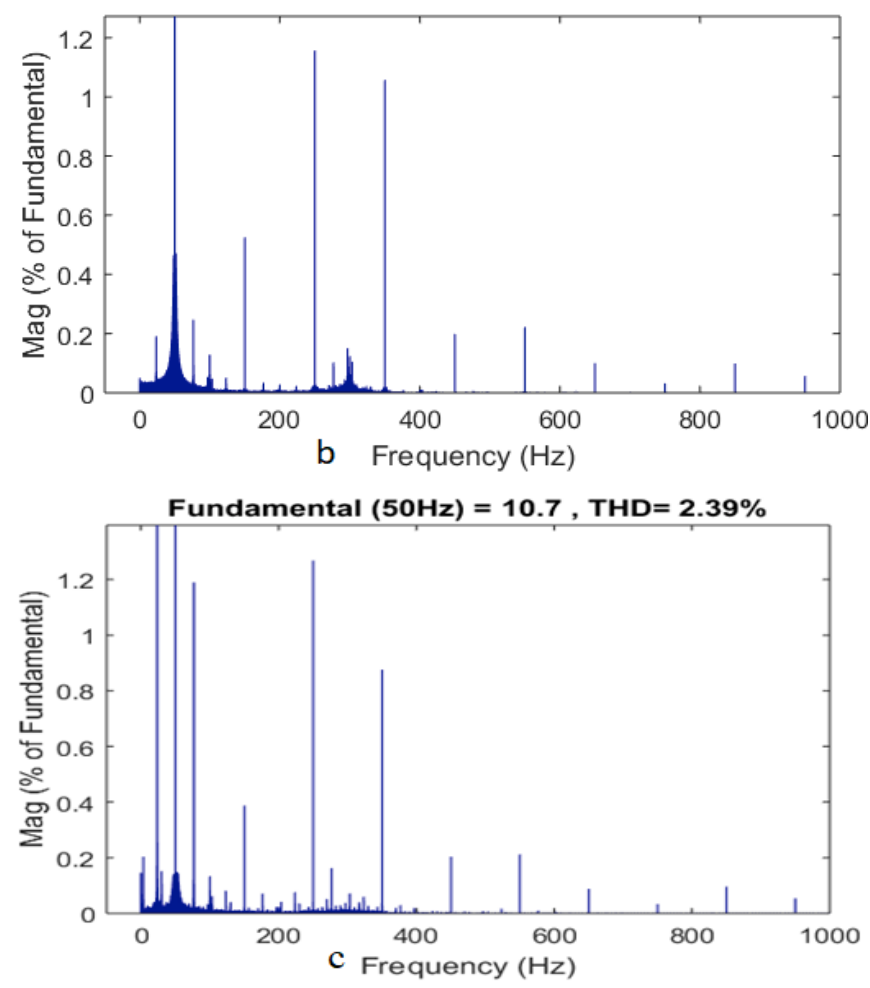

Fig. 17. THD of three correctors: a. PID b. PI c. modified PID

\section{Comparative study of three correctors}

The comparative study of correction in terms of overshoot (D), speed, almost no static error for all three regulators, response time ( $\mathrm{Tr}$ ) and in terms of current $\mathrm{TDH}$ is summarized in Table 4.

Table. 4. Comparative study of three regulators

\begin{tabular}{|l|c|c|c|c|}
\hline Magnitude & \multicolumn{2}{|c|}{ Voltage Vdc } & \multicolumn{2}{c|}{ Output Current } \\
\hline Criteria & $\mathrm{D}(\%)$ & $\operatorname{Tr}(\mathrm{s})$ & $\operatorname{Tr}(\mathrm{s})$ & THD (\%) \\
\hline PI & 17 & 1.1 & 0.18 & 3.01 \\
\hline PID & 46 & 0.38 & 0.253 & 6.15 \\
\hline MPID & 2.4 & 0.4 & 0.7 & 2.39 \\
\hline
\end{tabular}

This table shows that, despite significant response time, the modified PID controller injects a current with a harmonic distortion better than corrective PI and conventional PID and low overrun for the DC link voltage.

\section{Conclusion}

This work was dedicated to the study and a control loop design of a three-phase inverter connected to the grid in order to improve the quality of the energy injected from a photovoltaic conversion chain. A control in the $d-q$ synchronous reference frame modified by PID controller has been proposed to ensure a control of the output inverter currents and the DC link voltage. Simulation results of the proposed system in the Matlab / Simulink have proven the effectiveness and robustness of the correction in presence of disturbance. In addition, the current injected to the grid have a sinusoidal form with a harmonic distortion of $2.39 \%$ with the PID controller modified compared to conventional PID and PI corrector which give respectively 3.01 and $6.15 \%$.

Despite its performances, the modified PID controller remains a corrector whose parameters depend on constant values. Therefore, the change in the past (PV system depends on the weather) is a limit as well as the experimental setting of the regulator's parameters when the system is slow. However it is necessary to consider other techniques in particular take into account or will face changes in system parameters: the neural commands for example.

\section{References}

1. B. Hamza, modelling and control of a chain of photovoltaïque conversion 2016. (Thesis)

2. A. Menadi, Control by intelligent techniques of a photovoltaic system connected to the grid. 2016. (Thesis)

3. J. Paul Gaubert, Photovoltaic generator with direct control of power and connected with the addition of services to the distribution network. 2016. (Article)

4. B. Boukezata, A. Chaoui, and J. P. Gaubert. Photovoltaic solar system connected to the electrical network and associated with a parallel active filter. Symposium of Electrical Engineering 2014, Cachan, French, 2014. (Article)

5. R. Layate, C. Bharatiraja, R. Palanisamy and Subhransu Sekhar. Hysteresis Current Controller based Transformerless Split Inductor-NPC - MLI for Grid Connected PV-System. Procedia Engineering, 64 (IConDM):224-233, 2013. (Article)

6. N. Hamrouni, M. Jraidi, A. Dhouib, and A. Cherif. Design of a command scheme for grid connected PV systems using classical controllers. Electric Power Systems Research, 143: 503-512, 2017. (Article)

7. S. Lalouni and D. Rekioua, Optimal control of a grid connected photovoltaic system with constant switching frequency. Energy Procedia, 36: 189-199, 2013. (Article)

8. N. Altin, I. Sefa. dSPACE based adaptive neuro-fuzzy controller of interactive grid inverter. Energy Conversion and Management, 56: 130-139, 2012. (Article)

9. M. Boudjedaimi, P. Wira, D. O. Abdeslam, S. Djennoune, and J. P. Urban. Control of an inverter with 
neuromimic approaches for the compensation of harmonic currents in electrical networks. International Conference on Electrical Engineering and its Applications (ICEEA), 2008.

10. B. Sujatha and G. Anitha. Enhancement of PQ in grid connected PV system using hybrid technique. Ain Shams Engineering Journal, 2016. (Article)

11. J. Hu, Predictive Direct Flow Control A New Control Method of Voltage Source Inverters in Distributed generation applications. www.mdpi.com/journal/energies, 10(4) :428 2017. (Article)

12. A.Rufer, electronic power DC / DC Conversion. Power electronic laboratory, -.

13. B. Bendib, H. Belmili, and F. Krim. A survey of the Most Used MPPT methods: Conventional and advanced algorithms applied for photovoltaic systems. Renewable and Sustainable Energy Reviews, 45: 637-648, 2015. (Article)

14. N. Aouchiche, M. S. Cheikh Ait and A. Malek. Continuation of the maximum power point of a photovoltaic system by the methods of the incremental conductance and perturbation \& observation. Revue of Renewable Energies, Vol. 16 N$^{\circ} 3$ (2013) 485 - 498, 2013.

15. A. Bouzidi, Diagnosis and control of photovoltaic conditioning systems: case of a system connected to the electricity grid. Master, 2016.

16. J. Jose Pascual Camacho, Contribution to the modeling and control of a UPFC in connection with the development of intelligent networks (Smart Grids). (Master). 